\title{
Physical exercise and psychological well being: a critical review
}

\author{
Deirdre Scully, John Kremer, Mary M Meade, Rodger Graham, Katrin Dudgeon
}

\begin{abstract}
Summary
The relation between physical exercise and psychological health has increasingly come under the spotlight over recent years. While the message emanating from physiological research has extolled the general advantages of exercise in terms of physical health, the equivalent psychological literature has revealed a more complex relation. The paper outlines the research evidence, focusing on the relation between physical exercise and depression, anxiety, stress responsivity, mood state, self esteem, premenstrual syndrome, and body image. Consideration is also given to the phenomena of exercise addiction and withdrawal, and implications for exercise prescription are discussed.
\end{abstract}

\section{Introduction}

The positive role that physical exercise can play in the prevention and treatment of a range of medical conditions has received a great deal of attention over recent years, with numerous high profile reports supporting the popular message that exercise is good for you. ${ }^{1-3}$ In addition, research has identified the long term protection that regular exercise affords against a plethora of somatic complaints, including coronary heart disease, hypertension, a number of cancers, diabetes, and osteoporosis. ${ }^{45}$ Following from these findings, recommendations for exercise regimens emphasise the physical benefits that accompany increased physical activity, for example, with the American College of Sports Medicine (ACSM) advocating that "Every US adult should accumulate 30 minutes or more of moderate-intensity physical activity on most, preferably all, days of the week" ${ }^{6}$

Unfortunately, while the somatic benefits associated with physical exercise are well documented, hard evidence to support an equivalent relation between exercise and psychological well being is less plentiful. Indeed, neither the ACSM guidelines nor many of the available international public policy documents on physical activity make specific recommendations concerning exercise and mental health. Of the 17 documents reviewed by Blair et $a l^{7}$ only two make mention of the psychological benefits associated with physical activity. ${ }^{89}$ This is true despite the fact that, when asked about perceived health benefits of exercise, general practitioners are most likely to mention psychosocial benefits such as relaxation, increased social contact, promotion of self care, and self esteem. ${ }^{10}$

The interview survey of Smith et $a l^{10}$ bolsters a notion that has gained popularity both in the popular press and the academic community, namely that the psychosocial benefits of physical exercise may equal if not surpass the physiological benefits. The present paper aims to examine critically the evidence presented in support of this contention, before progressing to practical recommendations on the prescription of exercise regimens for the treatment of a range of psychological problems.

\section{Physical activity and psychological well being}

Over the last decade there have been several extensive reviews of the exercise psychology literature, which together offer positive if guarded support for the role that exercise can play in the promotion of positive mental health. ${ }^{11-13}$ This optimism is founded on growing numbers of controlled studies which have identified the positive effects of exercise, most often among clinical populations. At the same time, caution is expressed both in relation to the direction of causality and in the use of reductionist arguments to interpret findings. In the words of Rejeski ${ }^{14}$ "it is misguided to theorize that explanations for psychosocial outcomes will ultimately be reduced to some physiological system (e.g. cardiac-related cortical activity) or neurochemical activity" ( $p$ 1053). Instead, what Rejeski and others maintain is that perceived psychosocial benefits may occur in the absence of clearly identifiable changes in physiological parameters, just as it is possible to establish physiological changes in the absence of any perceived psychological benefits.

In a wide ranging literature review, McAuley ${ }^{13}$ has considered the relation between exercise and both positive and negative psychological health. In common with other review articles, McAuley identifies the positive correlation between exercise and self esteem, self efficacy, psychological well being, and cognitive functioning, and the negative correlation between exercise and anxiety, stress, and depression. While such information can be used to support the general benefits of exercise, it falls short of suggesting practical guidelines on how exercise may be used to alleviate particular symptoms, and, just as significantly, which forms of exercise are likely to be most beneficial in which circumstances. In addition, establishing the direction of causality has proved difficult - that is, did psychological well being precede, follow, or operate independently from a particular exercise regimen? With this in mind, it is unsurprising that reviewers remain critical of the methodological limitations of much of the exercise psychology literature (see Mutrie and Biddle ${ }^{11}$ ).

In a more innovatory critique of the literature, Rejeski ${ }^{14}$ attempted to frame the psychosocial outcomes of exercise in terms of a 
dose-response relation, a relation that had previously enjoyed popularity not in the exercise psychology but in the exercise physiology literature. According to Shepherd, ${ }^{15}$ one of the primary issues for exercise physiologists (alongside other health care professionals) centres on establishing the specific association between physical activity undertaken (a product of intensity, frequency, and duration) and biological responses (assessed by improvement in aerobic fitness or health). Despite unresolved concerns over the application of the research paradigm, ${ }^{15}$ many public policy initiatives continue to be based on recommendations derived from related research.

According to Rejeski, while the doseresponse relation may have heuristic value in relation to the physiology of exercise, in terms of psychological effects it fails to account for the cognitive and emotional experiences of the exerciser. Hence the complexity of the relation, in terms of both dose (activity type, frequency, intensity, and duration) and possible responses, makes it difficult to envisage research ever having the potential to move from description to prescription in relation to mental health.

Recent literature continues to urge caution when extrapolating from the physiological to the psychological, particularly as so few studies are exploring the dose-response relation between exercise and psychosocial outcomes. Rejeski ${ }^{14}$ reviews only four such studies, with the most significant conclusion derived from this work being that there appears to be a ceiling level in terms of psychosocial effects. More specifically, these studies ${ }^{16}{ }^{17}$ have suggested that low to moderate levels of aerobic exercise are better than traditional demanding (anaerobic) exercise programmes in terms of enhancing mood and improving psychological functioning.

There is greater difficulty in establishing precise guidelines with regard to the intensity and duration of exercise, partly because of methodological inconsistencies across studies reviewed, but also reflecting on differences between the psychological functions being evaluated. At the level of general mental health, the literature therefore remains inconclusive as to the relation between exercise regimens and overall psychological well being, and, with this in mind, it is towards the specific effects of exercise on particular psychological functions and conditions that attention has turned.

In 1992, the International Society of Sport Psychology ${ }^{18}$ endorsed the position statements earlier issued by the American National Institute of Mental Health ${ }^{19}$ which described the link between regular exercise and psychological well being. Briefly, these consensus documents posited that particular psychological dysfunctions, most notably depression, anxiety, and stress, can benefit from involvement in physical activity. The evidence for a significant and positive relation between physical activity and psychological variables is taken as compelling for mentally healthy individuals ${ }^{20}{ }^{21}$ but is seen as even stronger for the psychiatric population. ${ }^{22}$ This may not be unexpected-for example, given that the normal population "score at the low end of depression scores and therefore, have relatively little room for improvement", p $161 .{ }^{23}$ Much of the existing literature on exercise and mental health has focused on changes in anxiety, depression, mood, self esteem, and stress reactivity. Alongside these, for the purpose of this review it was decided also to examine two less frequently cited areas of research, those dealing with exercise effects on premenstrual syndrome (PMS) and also the relation between exercise and body image.

DEPRESSION

Martinsen $^{22}$ reviewed the literature dealing with the effects of exercise on patients diagnosed as suffering from clinical depression. Initially, he found that such patients tended to be physically sedentary and were characterised by a reduced physical work capacity compared with the general population. In itself this finding immediately provides an argument for the integration of physical fitness training into comprehensive treatment programmes for depression, while at the same time signalling the difficulties that may be involved in implementing an exercise regimen with a population who are not predisposed towards exercise.

Although a number of studies stress the importance of using aerobic exercise in the treatment of clinical depression, ${ }^{23}$ Martinsen found that the antidepressant effects linked with non-aerobic exercise were equally effective. He also found that those who continued to exercise regularly after termination of a one year training programme were found to have lower depression scores than those who were sedentary. In addition, the patients themselves were found to be very much appreciative of the use of exercise as a form of treatment and, as Martinsen states, the patients ranked exercise as, "the most important element in comprehensive treatment programmes for depression" (p 388).

In 1990, North et $a l^{24}$ conducted a metaanalysis based on 80 studies conducted between 1969 and 1989, and included 290 effect sizes in their analysis. The results provided positive support for a relation between physical exercise and depression. In particular, it was concluded that acute and chronic exercise effectively reduced clinical depression. All groups of participants, regardless of gender, age, or health status, experienced the antidepressant effects of exercise, with the greatest benefits noted among those experiencing medical or psychological care. The mode and duration of exercise were also examined and it was found that both aerobic and non-aerobic exercise operated as effective antidepressants. However, the authors concede that additional research should focus on the proposed psychotherapeutic benefits of non-aerobic exercise, given that numerous studies do not concur with this finding - for example, Folkins and Sime ${ }^{25}$ and Sachs. ${ }^{26}$ Finally, the authors also examined issues relating to length of exercise programme, number of sessions, as well as intensity and frequency of exercise. Insufficient 
data relating to the latter two elements yielded no firm conclusions, but the meta-analysis did suggest that the greatest improvements in depression were found after 17 weeks of exercise (albeit that effects were found from four weeks onwards). Likewise, it was suggested that the greater the number of exercise sessions the greater the decrease in depression.

A recent narrative review ${ }^{27}$ has criticised the meta-analysis of North et al on methodological and interpretative grounds, urging that their conclusions and recommendations should be viewed with caution. In contrast, Morgan $^{27}$ is sympathetic towards a monograph reviewing the psychological effects of aerobic fitness training. ${ }^{28}$ Paradoxically, many of the conclusions of both studies are identical, in that depression was reduced after aerobic exercise for men and women, all adult age groups, across survey and experimental studies, and the effects were greatest among clinical samples.

Finally, a recent paper by Nicoloff and Schwenk ${ }^{29}$ attempts to integrate current research with a view to providing physicians with practical guidelines for exercise prescription as an adjunct to other forms of psychotherapy. Despite acknowledging that no research based guidelines exist for recommending exercise type, frequency, intensity, and duration, the authors invoke prescriptions suggested by Hill $^{30}$ which basically concur with those proposed by the ACSM. ${ }^{98}$ Such programmes advocate aerobic exercise conducted at 60$70 \%$ of maximal heart rate, for $30-40$ minutes, twice to five times a week.

In conclusion, on the basis of existing literature, it seems safe to accept that physical exercise regimens will have a positive influence on depression, with the most powerful effects noted among clinical populations. Limited evidence would also suggest that aerobic exercise is most effective, including activities such as walking, jogging, cycling, light circuit training, and weight training, and that regimens extending over several months appear to yield the most positive effects.

ANXIETY

To date, there have been over 30 published reviews dealing with the anxiolytic effects of exercise and physical activity. One review ${ }^{31}$ concludes that regardless of anxiety measures taken (trait or state, behavioural, self report, physiological), or exercise regimen invoked (acute $v$ chronic), the results point to a consistent link between exercise and anxiety reduction. Furthermore, a meta-analysis ${ }^{32}$ specifically examining studies that distinguish between those who are coping with stress and those who are not concluded that aerobic exercise training programmes were effective in reducing anxiety, particularly among those experiencing chronic work stress. Their overall effect sizes were comparable with those found by other meta-analyses of the exercise-stress literature, as well as other forms of psychotherapy used to reduce anxiety. ${ }^{33}$ Finally, recent research in this area ${ }^{34}{ }^{35}$ has refuted criticisms of earlier studies that imply that anxiety reduction after exercise represents no more than a methodological artefact ${ }^{36}$; instead, the effect does appear to be real and substantial.

At the same time, explicating the variables that mediate the relation between exercise and anxiety reduction has proved problematic, a task made doubly difficult because so few studies specify levels of intensity, duration, and/or length of exercise programme. To date, it can be inferred that most research studies have involved aerobic exercise, with the few studies examining non-aerobic activities-for example, strength/flexibility training-actually showing slight increases in anxiety. Although further research is obviously needed, it does appear that aerobic activity is more beneficial for anxiety reduction.

No consensus of opinion emerges from existing reviews and meta-analyses on the level of exercise intensity and its duration. For example, Landers and Petruzzello ${ }^{31}$ report conflicting results from a large number of studies. Some suggest low intensity exercise (walking, jogging at $40-50 \%$ of maximal heart rate), while others argue that moderately intensive exercise $(50-60 \%$ of maximum heart rate) is better, and yet others argue that high intensity activity (70-75\% of maximum heart rate) is most beneficial. ${ }^{37}$ Given this lack of consensus, a sensible compromise position in relation to prescription appears to be that originally proposed by Franks and Jette. ${ }^{38}$ That is, for the individual to work with an adjustable level of intensity, chosen by him/herself in consultation with a physician. This solution is especially attractive in the light of the goal setting literature which argues that self selected goals receive greater commitment from the participant.

The duration of individual training sessions has been considered across individual studies, with somewhat surprising results. According to recent research, even a single, five minute exercise bout may be sufficient to induce an anxiolytic effect. ${ }^{3135} 37$ In terms of the length of training programmes, both clinical and nonclinical studies have shown that the largest anxiolytic effects are noted when programmes have run from 10 to 15 weeks or even longer, with smaller effects observed for programmes lasting less than nine weeks.

In conclusion, the literature unequivocally supports the positive effects of exercise on anxiety, with short bursts of exercise appearing to be sufficient, and, in addition, the nature of the exercise does not appear to be crucial. As with depression, the most positive effects are noted among those who adhere to programmes for several months.

STRESS RESPONSIVITY

A related literature has considered how exercise may protect against stress, although whether this should be regarded as psychological or physiological research is questionable. This aside, the available research suggests that increases in physical condition or improved fitness are likely to facilitate the individual's capacity for dealing with stress. In reviewing this work, ${ }^{39}$ a distinction has been made 
between research based on either cross sectional (categorising participants as "fit" or "unfit" and then observing differences between the groups) or longitudinal (using training and control groups) designs. Results derived from both procedures are best described as equivocal; while the majority do show that physical fitness correlates with a reduction in the physiological response to psychological stress, a smaller number of studies report negligible differences in stress reactivity between the physically fit and the less fit.

True experimental training studies remain rare, although more recent contributions are attempting firstly to manipulate levels of aerobic fitness experimentally and secondly to correlate these fitness levels with stress responsivity. In addition, a number of studies have found that aerobic exercise does appear to influence stress responses..$^{40-42}$ In each of these studies, comparisons have been drawn between aerobic exercise and anaerobic strength training, with participants typically exercising at least three times a week at moderate intensity for 12 weeks. While the effect appears robust, other studies that have employed a similar exercise paradigm and have used similar measures have failed to replicate these results. ${ }^{43-45}$ As a consequence, discussion often revolves around methodological concerns, and definitive conclusions remain elusive.

In conclusion, while it may be that aerobically fit individuals do show a reduced psychosocial stress response, the role that exercise can play is probably best described as preventive rather than corrective, and the stress response itself remains only partially understood. Clearly, this work lies at the interface between physiology and psychology and hence raises a great many unanswered questions about the stress response itself and its relation to physiological and psychological symptoms. With these caveats in mind, it would appear that a regimen of aerobic exercise (continuous exercise of sufficient intensity to elevate heart rate significantly above resting pulse rate for over 21 minutes duration) may significantly enhance stress responsivity, and in particular stress that is related to lifestyle or work.

MOOD STATE

Numerous studies have investigated the mood enhancing properties of exercise and have shown that exercise can indeed have a positive influence on mood state. At the same time, the early optimism generated by studies of clinical samples has been tempered by the discovery that the effects of exercise on mood state may not be as pervasive as earlier thought. For example, Dishman ${ }^{46}$ and Frazier and Nagy $^{47}$ have identified individuals who were not initially depressed or anxious, who failed to match a post-exercise mood enhancement as had been noted with clinical samples. On the other hand, it has also been shown that individuals may self report an improvement in mood state without a corresponding improvement being detected by the psychometric test of mood. ${ }^{48}$ These and other methodological concerns have been addressed. ${ }^{36}$ In particular, the fact that most studies examining exercise effects on mood have utilised the Profile of Mood States (POMS) ${ }^{49}$ has been criticised because the test was initially validated for use in clinical populations and includes only one positive mood dimension (see LaFontaine et $\left.a l^{33}\right)$. In the light of these and other criticisms, ${ }^{36}$ future reliance on the POMS as the primary measure of mood state in exercise research must be questioned.

A meta-analysis by McDonald and Hodgdon ${ }^{28}$ appeared to confirm a clear relation between exercise and positive moods, with significant effect sizes being shown for all six subscales of the POMS. However, more recent research suggests that this relation may be quite complex and demands further clarification. For example, Lennox et $a \bar{l}^{0}$ compared aerobic, anaerobic, and waiting list control groups and found no significant improvements in long term mood states among non-clinical samples. By comparison, other studies found improvements in mood states of female exercisers. $^{5152}$ Both of these latter studies examined chronic exercise over a similar duration to that used by Lennox et al, although the intensity of exercise was less pronounced. These studies highlight the possibility that gains in physical fitness may operate independently of mood, and hence it may be possible to show physical fitness gains in the absence of mood effects and vice versa. In comparison, acute aerobic exercise has been shown to be associated with significant positive mood changes. ${ }^{53}$ Two recent studies examining the benefits of acute exercise have also found mood benefits associated with exercise. ${ }^{545}$ Steinberg et $a \bar{l}^{4}$ compared different intensity (low impact/ high impact) aerobic exercise of 25 minutes duration with a video watching control group and found increases in positive moods and decreases in negative moods after exercise. Another study ${ }^{55}$ adopting a slightly different approach set out to determine if a lengthy bout of acute aerobic exercise would attenuate the adverse mood effects induced by prescribed $\beta$ blockers to normal healthy individuals. Results showed that one hour of moderate $(50 \%$ of maximum) treadmill walking was able to produce mood states comparable with those recorded for participants in placebo trials. The authors concluded that exercise prescription should be considered a highly desirable adjuvant therapy in cases where drug therapy is necessary.

Overall these results do indicate that various forms of exercise, both aerobic and anaerobic, can be associated with an elevation of mood state, particularly for clinical samples, although given the diversity of results it is likely that more than one underlying mechanism may be implicated. The nature of these mechanisms, whether psychosocial, psychological, psychopharmacological, or psychophysiological, has yet to be understood.

SELF ESTEEM

In keeping with the other relations already examined, a positive link between exercise and self esteem has been established and in turn 
this appears to be strongest among those whose self esteem is low. ${ }^{13}$ However, the reported association is not without criticism. For example, most studies examined global self esteem, which is a relatively stable construct, rather than considering domain specific esteem. ${ }^{56}$ Furthermore, few studies have explored changes in self esteem over time, with most focusing on differences between exercisers and non-exercisers at a given point in time.

According to an early review, ${ }^{57}$ self esteem improved with participation in physical activity regardless of physical activity type. However, a meta-analysis ${ }^{58}$ that focused solely on self esteem in young children found a greater effect size for aerobic activities. A more recent review ${ }^{13}$ raises a number of methodological and conceptual concerns, but also concurs with previous reviews in identifying a positive association between physical activity and self esteem. Recent work in this area has tended to focus on the development of valid and reliable measures of self esteem, which in turn is regarded as multifaceted. For example, Fox ${ }^{59}$ has developed the physical self perception profile, which distinguishes between global self esteem and physical self esteem and which in turn has been related to factors including body image and sports competence. Subsequent work has been concerned with validation and in so doing has found further support for the notion that physical activity is associated with higher levels of self esteem in younger and older adult men and women. ${ }^{60-62}$

An emerging viewpoint suggests that the more specific subdomains of self esteem, in particular perceived sport competence, physical condition, attractive body, and strength, may be associated differentially with behaviour in various sports. For example, Sonstroem et $a l^{62}$ found that exercise in adult female aerobic dancers was associated with positive evaluations of their physical condition but with negative evaluations of their bodies. However, little can be said in terms of exercise prescription in the development of self esteem or its subcomponents because so few studies have considered such changes over time. In fact, only one study appears to have considered this in middle aged men in the context of a five month walking programme. ${ }^{56}$ The study showed a significant relation between improved aerobic capacity and a measure of physical esteem. Results indicate that the greatest degree of change over time was in the subdomain element of physical condition, and global level self esteem showed the smallest degree of change (although it was still significant).

While these associations are interesting, the literature provides little guidance as to which forms of exercise may be beneficial to which types of self esteem. That there is a relation is not questioned, but the nature of that relation has yet to be explored.

PREMENSTRUAL SYNDROME (PMS)

Despite anecdotal evidence pointing to a relation between exercise and PMS symptomatology, and the fact that negative effect, depression, and anxiety, are commonly associated with PMS, only a small number of studies have considered the potential benefits of exercise on PMS. One such study ${ }^{63}$ investigated the impact of a 12 week training programme on symptom severity in relation to primary dysmenorrhoea. Eighteen women who were diagnosed as suffering from dysmenorrhoea were assigned to a training programme which involved a 30 minute walk/jog session three times a week for 12 weeks. Their symptoms were subsequently compared with a non-exercising control group, and it was concluded that this form of exercise had ameliorated symptoms.

This and other examples of early research on PMS has tended to confirm that exercise has a prophylactic effect on a range of symptoms both physiological and psychological. ${ }^{64}{ }^{65}$ More recently, Choi and Salmon ${ }^{66}$ monitored the effect of various frequencies of exercise on PMS in a self selected sample across one menstrual cycle. Low exercise and sedentary groups showed no improvement in symptoms whereas the high exercise group experienced significantly fewer symptoms. Interestingly, competitive exercisers did not show improvements, perhaps indicating that strenuous exercise may be dysfunctional, and confirming earlier speculations ${ }^{67-69}$ relating to the negative effects of competitive exercising on anxiety and mood state. Likewise, Cockerill et $a l^{70}$ found that those who engaged in exercise more than four times a week reported higher tension, depression, and anger, whereas those who exercised two to three times a week had healthier mood state profiles.

As regards the type of exercise that appears most beneficial, a study ${ }^{71}$ that considered this looked at 23 premenopausal middle aged women engaged on either an anaerobic (strength training) or aerobic exercise programme which took place three times a week for one hour over a 12 week period. Participants completed a menstrual symptom questionnaire during their luteal phase once before the start of the programme and once more at its conclusion. While both aerobic and anaerobic exercise were shown to reduce premenstrual symptom severity, aerobic exercise appeared to have a more significant effect on premenstrual depression.

This study, along with previous research, ${ }^{72}$ suggests that it may not be necessary to reach aerobic capacity in order to alleviate the negative effects associated with PMS, and hence increased maximal oxygen consumption does not appear to be a causative factor. If this is the case then the question remains as to why exercise may be an effective treatment for PMS. Numerous explanations have been advanced, including the effect that exercise may have on the oestrogen:progesterone ratio. On the one hand, some research has indicated that sportswomen have lower levels of oestrogen than non-exercising women, while on the other hand, other studies have found no differences. ${ }^{73-75}$ Rather than assuming a direct relation between exercise and lowered oestrogen levels, Wells ${ }^{76}$ has suggested that these levels reflect reduced body fat, since adipose tissue has been identified as a source of oestro- 
gen. An alternative explanation highlights improved glucose tolerance during this stage of the cycle, as the symptoms of poor glucose tolerance are similar to those often reported by women who experience PMS, namely fatigue, depression, anxiety, and increased appetite. ${ }^{77}$ According to others, ${ }^{78}{ }^{79}$ the elevation of endorphin levels before menstruation may be a significant factor, and regular exercise may stabilise or prevent extreme variation in endorphin levels and thus decrease the effects of PMS.

In conclusion, although the evidence continues to point to the benefits of exercise for those who experience PMS, while less strenuous forms of non-competitive exercise appear most effective, the type of exercise, its duration, and length and in turn the reasons for improvement in symptoms still await clarification.

BODY IMAGE

In prescribing activity for both physical and psychological benefit, due caution must be taken to ensure that risk factors are not introduced that may attenuate the process of exercise induced psychological health. The gendered nature of physical activity cannot be disregarded in this debate, for while men may enjoy a symbiotic relationship with sport, too often in the past women's sport has been associated with sex role conflict and associated disorders. Fortunately, this picture may be changing rapidly but at the same time the relation between exercise and problems with body image should not be ignored, for either gender.

Despite significant gains in public acceptance and participation, ${ }^{80}$ women are still more likely to engage in non-competitive activities such as aerobics and keep fit, ${ }^{81}{ }^{82}$ which in turn may serve to reinforce the cult of thinness and femininity. Franzoi ${ }^{84}$ has described a tendency among women to focus on their body as an aesthetic statement whereas traditionally men have been more likely to attend to the dynamic aspects of their bodies, such as coordination, strength, and speed. This emphasis on the female form in exercise settings may foster feelings of social-physique-anxiety (SPA), constrain enjoyment of the activity itself, and may even be exacerbated by the nature of the clothing required. ${ }^{85}$ McAuley et $a l^{86}$ reported that SPA correlates with self presentational motives for exercise such as weight control and attractiveness, and is higher among women. ${ }^{87}$ Women consistently score higher than men on measures of self confidence with regard to their bodies and physical competence. ${ }^{88} 89$ Biddle $e t$ $a l,{ }^{90}$ among others, have emphasised the need for exercise promoters to address this issue of poor self confidence among women, and to think carefully about sporting venues and other contextual factors (for example, changing facilities) in order to make women feel more comfortable with their body image during exercise.

Body image itself refers to a multidimensional construct consisting of a set of cognitions and feelings about one's physique. Research shows that body image tends to be less positive among women, ${ }^{91}$ and is more closely linked to women's overall self esteem than men's. ${ }^{92}$ For example, in a national survey of 803 US women, over half reported globally negative evaluations of their body parts and a preoccupation with losing weight. ${ }^{93}$ The implications of such findings are considerable given that disturbances in body image have been so strongly implicated in the development of eating disorders ${ }^{94}$ and clinical depression..$^{95}$ Without doubt, physicians who advocate the adoption of exercise regimens must remain alert to these body related concerns when prescribing forms of physical activity.

When training and diet regimens are overly stringent, women in particular are susceptible to three distinct although interrelated disorders collectively referred to as the female athlete triad (FAT). Referring to disordered eating, amenorrhoea, and osteoporosis, FAT is the physical manifestation of a pathological adherence to exercise, often coupled with inappropriate diet. ${ }^{9697}$ In its position paper, the $\mathrm{ACSM}^{98}$ maintains that the syndrome can cause morbidity and mortality, and notes in particular that women involved in sports that emphasise low body weight for performance or appearance-for example, gymnastics and dance - are most at risk. Nattiv ${ }^{99}$ has characterised the typical sufferer as someone driven to excel, who equates leanness with improved performance, and who feels pressured to maintain a low body weight. Nattiv has further outlined criteria for screening those at risk, based on interviewing and physical examination.

What is more, not only may exercise be associated with body dissatisfaction, once undertaken, it may actually be implicated in the perpetuation of eating disorders and weight control. Davis et $a l^{100}$ have described the role that exercise may play in sustaining the cyclical repetitious nature of eating disorders, and have also outlined the manner in which exercise and self starvation may interact as mutual catalysts. ${ }^{101}$ Disordered eating practices and a drive for thinness or leanness are often accompanied by psychopathological consequences observable in depressive symptoms such as low energy and poor self esteem. ${ }^{102}{ }^{103}$ With these thoughts in mind, caution is required when recommending exercise practices which may provide a link in the chain of disordered eating or which may present itself as a dysfunctional response to body dissatisfaction.

\section{Exercise addiction and withdrawal}

Within the psychophysiology literature, an emerging research focus is on the notion of exercise addiction, ${ }^{104}{ }^{105}$ the contention being that the mood enhancing and analgesic properties associated with exercise are influenced by chemicals in the brain which are akin to opiates. ${ }^{106}$ Until recently, support for the existence of exercise addiction was meagre and often anecdotal. ${ }^{107-109}$ More recent research has suggested strong links between exercise addiction and eating disorders. ${ }^{110} 111$ For example, Davis et $a l^{110}$ found a significant relation between exercise dependence, weight preoccupation, and obsessive-compulsive personality traits in eating disordered women. Further- 
more, the same study showed a significant relation between amount of physical activity and obsessive-compulsiveness in high exercising women without eating disorders.

A related concept, that of withdrawal from habitual exercise, may also be relevant in the context of attempting to provide exercise prescription. ${ }^{112}$ Morgan and colleagues ${ }^{113}$ speculate that cessation of regular physical activity could result in dysphoric states-for example, increased anxiety, depression, restlessness, guilt. Indeed, a number of previous studies would concur with this speculation. ${ }^{114-116}$ However, yet again, despite the intuitive appeal of anecdotal examples, there is a limited amount of empirical research on the topic, and comparison across studies is not possible given the methodological differences surrounding deprivation periods and behavioural measures. ${ }^{113}$

Whether the mechanism for supposed exercise addiction is based on psychological factors (for example, personality types), physiological mechanisms (for example, endorphin dependence), or an interplay between the two has yet to be established. A recent workshop ${ }^{104}$ concluded that much more systematic investigation needs to be conducted before definitive conclusions can be made about exercise prescription. For example, a number of cautions were raised, including doubts about whether the syndrome of "exercise dependence" exists at all except as one facet of an eating disorder, ${ }^{111}$ the danger of confusing exercise adherence with exercise dependence and exercise addiction, ${ }^{117}$ and that the hypothesis for a "runner's high" - that is, that exercise releases endorphins which produce physiological dependence - is still only a hypothesis with little supportive evidence. ${ }^{118}$

Mental health and exercise prescription Taken as a whole, the review posits that a range of exercise regimens may be able play a therapeutic role in relation to a number of psychological disorders. At the same time, the research evidence to date does not provide unqualified support for the efficacy of exercise, and enthusiasm must be tempered with an acknowledgment of the dangers associated with exercise. Certainly, the literature does not indicate that exercise should be treated as a panacea or snake-oil for psychological malaise of whatever kind. Instead, it does suggest that different forms of physical exercise may be palliative in relation to particular conditions. Whether that exercise be non-aerobic, aerobic, or anaerobic, of short, medium, or long term duration, competitive or non-competitive, team or individual, single or multi session is not always clear, but there are suggestions that different psychological conditions respond differentially to alternative exercise regimens, and recent attempts to develop taxonomies of physical activity and mental health may offer a realistic starting point in attempting to draw together some of the diverse recommendations. ${ }^{30} 119$

As to explanations as to why more definitive conclusions cannot be reached at this stage, then three factors stand out. Firstly, the research base remains thin, and primary data are not extensive. To overcome this problem there is a need for large scale multidimensional experimental programmes, associated with multivariate analyses of covariance, in order to clarify the complexities of the relations between physical exercise and psychological health. Secondly, it is not yet clear how psychological and physiological processes and functions interact in the determination of outcomes. The grey areas of confusion are most apparent when dealing with psychophysiological responses such as stress reactivity. Indeed, it could be that cartesian notions of mind-body dualism continue to drive a wedge between the physiological and the psychological. Greater collaboration between the two disciplines would undoubtedly help this situation. Thirdly, and in a related vein, the primary mechanisms that underlie the relation between exercise and psychological well being remain poorly understood. It would also be fair to say that a great deal of the literature remains descriptive or atheoretical. That is, it is able to describe how exercise and psychological well being interact but it has shied away from asking or exploring why the relation is as it is. Here psychophysiologists have led the field in attempting to provide explanations, including consideration of the influence of catecholamines, body temperature, and endorphins. Psychosocially, issues relating to lifestyle, boredom, and "time out" have also been implicated but how, when, and where each factor may be involved is once more a matter for debate. In all likelihood, given the complexities of the relations between exercise and well being outlined above, it is unlikely that any single theory, model, or hypothesis will suffice. Instead, multiple perspectives must be employed.

Finally, it is also important to recognise the difficulties associated with adherence to exercise regimens. No matter how beneficial such schemes may be, if there is no willingness to exercise voluntarily then the practical utility of exercise is diminished dramatically. Hence recommendations must be put in context of adherence research. For example, it has been maintained that only $10 \%$ of the population is committed to physical activity; $20 \%$ will start but not adhere to exercise; $40 \%$ will promise to start an exercise programme; $20 \%$ need to be convinced to participate in exercise; and $10 \%$ are not interested in any form of organised or recommended activity. ${ }^{120}$ Such research highlights the deep rooted resistance to taking exercise among large sections of the population, sections that lead essentially sedentary lives, with inactivity rates of $25 \%$ and $15 \%$ recently recorded for American and British populations respectively $^{6}$, and with the likelihood of even higher rates among those with psychological problems.

In exploring the population's apparent resistance to physical activity, a recent review has considered some of the theoretical models utilised in designing exercise interventions. ${ }^{121}$ As with the arguments advanced above in relation to explanations for exercise induced mental 
health benefits, they conclude that no individual model can sufficiently explain exercise behaviour or how best to intervene. However, in proposing future directions in the area, it is interesting to note that the authors draw on largely psychological components as offering promise for encouraging greater participation. Specific factors outlined include enhancing self efficacy, increasing enjoyment of the activity, enhancing social support, and promoting the perceived benefits of exercise. While it is not within the scope of this paper to explore public policy initiatives for exercise promotion further, the authors hope that a comprehensive review of the literature pertaining to exercise and mental health would assist in any future developments.

All these arguments aside, general practitioners remain the ideal mechanism by which to promote exercise regimens. ${ }^{122}{ }^{123}$ At the same time, recent surveys suggest that, despite a generally favourable reception from general practitioners themselves, their role is not without problems, particularly in relation to the referral system, their lack of knowledge of exercise recommendations, and difficulty in evaluating community health promotion schemes. ${ }^{124125}$ Simultaneously, "exercise by prescription" schemes are gaining in popularity ${ }^{10}$; a recent newspaper article reports on one fundholding general practitioner in Warrington, Cheshire who has invested practice funds in opening up a medical centre gym for his patients. ${ }^{126}$

This level of enthusiasm for exercise promotion makes it all the more important that researchers, physicians, and exercise practitioners continue to work together to develop sound guidelines. This will be of practical benefit to the patient, and will also advance our understanding of the interplay between exercise and well being, allowing us to develop a firm foundation from which to make recommendations in the years to come. General recommendations are now commonly accepted as to the somatic benefits that accrue from exercise; the relation between exercise, fitness, and general cognitive functioning is now also receiving closer scrutiny. ${ }^{127}$ Alongside this research activity, now is the time to develop more specific guidelines relating to psychological benefits of exercise, taking due cognisance of psychosocial variables-for example, gender, age, previous mental health, environment - and recognising that the picture that will be revealed will not be as unidimensional as previous work may have implied.

1 Department of Health. Promoting better health. London: HMSO, 1996.

2 Royal College of Physicians. Medical aspects of exercise: benefits and risks. London: RCP, 1991

3 Allied Dunbar National Fitness Survey. Main findings. London: Sports Council and Health Education Authority, 1992.

4 Powell KE, Blair SN. The public health burdens of sedentary living habits: theoretical but realistic estimates. Med Sci Sports Exerc 1994;26:851-6.

5 Hillsdon M, Thorogood M. A systematic review of physical activity promotion strategies. Br f Sports Med 1996;30: 84-9.

6 Pate RR, Pratt M, Blair SN. Physical activity and public health: a recommendation from the Centers fro Disease health: a recommendation from the Centers fro Disease
Control and Prevention and the ACSM. $¥ A M A$ 1995;273: 402-7. 7 Blair, SN, Booth, M, Gyarfas, I, et al. Development of public policy and physical activity
Sports Med 1996;21:157-63.

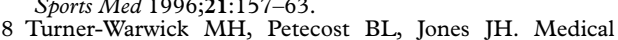
Turner-Warwick MH, Petecost BL, Jones JH. Medical
aspects of exercise. FR Coll Physicians Lond 1991;25:193-6. 9 Hardman AE, Blair SN. Physical activity, health, and well-being: a summary of the Consensus Conference. Res $Q$ Exerc Sport 1995;66:ii.

10 Smith PA, Gould MM, See Tai S, et al. Exercise as therapy? Results from group interviews with general practice teams involved in an inner-London 'prescription for exercise' scheme. Health Ed f 1996;55:439-46.

11 Mutrie N, Biddle SJH. Effects of exercise on non-clinical populations. In: Biddle SJH, ed. European perspectives on exercise and sport psychology. Champaign, IL: Human Kinetics, 1995:50-70

12 Martinsen EW. Effects of exercise on mental health in clinical populations. In: Biddle SJH, ed. European perspectives on exercise and sport psychology. Champaign, IL: Human Kinetexercise and sport

13 McAuley E. Physical activity and psychosocial outcomes. In: Bouchard C, Shephard RJ, Stephens T, eds. Physical activity, fitness, and health. Champaign, IL: Human Kinetics, 1994:551-68.

14 Rejeski WJ. Dose-Response issues from a psychosocial perspective. In: Bouchard C, Shephard RJ, Stephens T, eds. Physical activity, fitness, and health. Champaign, IL: Human Kinetics, 1994:1040-55.

15 Shephard R. Aerobic fitness and health. Champaign, IL: Human Kinetics, 1994

16 Moses J, Steptoe A, Matthews A, et al. The effects of exercise training on mental well-being in the normal population: a controlled trial. F Psychosom Res 1989;33:47pop

17 Sexton H, Maere A, Dahl NH. Exercise intensity and reduction in neurotic symptoms. Acta Psychiatr Scand 1989;80:231-5.

18 International Society of Sport Psychology. Physical activity and psychological benefits: a position statement. The Sport Psychologist 1992;6:199-204

19 Morgan WP, Goldston SE, eds. Exercise and mental health. New York: Hemisphere, 1987.

20 Berger BG, Owen DR. Stress reduction and mood enhancement in four exercise modes: swimming, body conditioning, Hatha yoga and fencing. Res $Q$ Exerc Sport 1988;59: 148-59.

21 Biddle S, Mutrie N. Psychology of physical activity and exercise. London: Springer Verlag, 1991.

22 Martinsen EW. Benefits of exercise for the treatment of depression. Sports Med 1990;9:380-9.

23 LaFontaine TP, DiLorenzo TM, Frensch PA, et al. Aerobic exercise and mood. Sport Med 1992;13:160-70.

24 North TC, McCullagh P, VuTran, Z. Effect of exercise on depression. Exerc Sport Sci Rev 1990;18:379-415.

25 Folkins CH, Sime WE. Physical fitness training and mental health. Am Psychol 1981;36:373-89.

26 Sachs ML. Exercise and running: effects on anxiety, depression and psychology. Humanistic Education Development 1982;21:51-7.

27 Morgan WP. Physical activity, fitness and depression. In: Bouchard C, Shephard RJ, Stephens T, eds. Physical activity, fitness, and health. Champaign, IL: Human Kinetics, 1994:851-67.

28 McDonald DG, Hodgdon JA. The psychological effects of aerobic fitness training: research and theory. New York: Springer-Verlag, 1991

29 Nicoloff G, Schwenk TL. Using exercise to ward off depression. Physician and Sportsmedicine 1995;23:44-58.

30 Hill JW. Exercise prescription. Prim Care 1987;14:817-25.

31 Landers DM, Petruzzello SJ. Physical activity, fitness and anxiety. In: Bouchard C, Shephard RJ, Stephens T, eds. Physical activity, fitness, and health. Champaign, IL: Human Kinetics, 1994:868-82.

32 Long BC, Stavel RV. Effects of exercise training on anxiety: a meta-analysis. Fournal of Applied Sport Psychology 1995;7: $167-89$.

33 Lambert MJ, Shapiro DA, Bergin AE. The effectiveness of psychotherapy. In: Garfield SL, Bergin AE, eds. Handbook of psychotherapy and behavior change. New York: Wiley, 1986:157-211.

34 Petruzzello SJ. Anxiety reduction following exercise: methodological artifactor 'real' phenomenon? fournal of Sport and Exercise Psychology 1995;17:105-11.

35 McAuley E, Mihalko SL, Bane SM. Acute exercise and anxiety reduction: Does the environment matter? Fournal of Sport and Exercise Psychology 1996;18:408-19.

36 Gauvin L, Brawley LR. Alternative psychological models and methodologies for the study of exercise and affect. In: Seraganian P, ed. Exercise psychology: the influence of physical exercise on psychological processes. New York: Wiley, 1993: 146-71

37 Tate AK, Petruzzello SJ. Varying the intensity of acute exercise: implications for changes in affect. $\mathcal{F}$ Sports Med Phys Fitness 1995;35:1-8.

38 Franks BD, Jette M. Manifest anxiety and physical fitness. National College of Physical Education Association for Men Annual Proceedings Chicago, 1970.

39 Fillingim RB, Blumenthal JA. The use of aerobic exercise as a method of stress management. In: Lehrer PM, Woolfolk RL, eds. Principles and practice of stress management. London: Guilford, 1993:443-62.

40 Blumenthal JA, Maddem DJ. Effects of aerobic exercise training, age and physical fitness on memory search performance. Psychol Aging 1988;3:230-85. 
41 Sherwood A, Light KC, Blumenthal JA. Effects of aerobic psychosocial stress in normotensive and borderline hyperpsychosocial stress in normotensive and borderline hyper-
tensive Type A men: a preliminary report. Psychosom Med tensive Type A m

42 Blumenthal JA, Fredrikson M, Kuhn CM, et al. Aerobic exercise reduces levels of cardiovascular and sympathoadrenal responses to mental stress in subjects without prior evidence of myocardial ischemia. Am f Cardiol 1990;65:938.

43 Roskies E, Seraganian P, Oseasohn R, et al. The Montreal Type A Intervention Project: ajor findings. Health Psychol 1980 A Intervent

44 Sinyor D, Golden M, Steiner Y, et al. Experimental manipulation of aerobic fitness and the response to psychosocial stress: heart rate and self-report measures. Psychosom Med 1986;48:324-37.

45 Sothmann M, Hart B, Horn T. Plasma catecholamine response to acute psychological stress in humans: relation to aerobic fitness and exercise training. Med Sci Sport Exerc 1991;23:860-7.

46 Dishman R. Mental health. In: Seefeldt V, ed. Physical activity and well-being. Reston, VA: AAPHERD, 1986:303-41.

47 Frazier SE, Nagy S. Mood state changes of women as a function of regular aerobic exercise. Percept Mot Skills 1989;68:283-7.

48 Madden DJ, Blumenthal JA, Allen PA, et al. Improving aerobic capacity in older adults does not necessarily lead to improved cognitive performance. Psychol Aging 1989;4: 307-20.

49 McNair DM, Lorr M, Droppleman LF. Psychological effects of acute physical activity. Arch Phys Med Rehabil 1971;52:422-5.

50 Lennox SS, Bedell JR, Stone AA. The effect of exercise on normal mood. $\mathcal{F}$ Psychosom Med 1990;34:629-36.

51 Agaroff JA, Boyle GJ. Aerobic exercise, mood states and menstrual cycle symptoms. F Psychosom Res 1994;38:18392.

52 Cramer SR, Nieman DC, Lee JW. The effects of moderate exercise training on psychological well-being and mood state in women. F Psychosom Res 1991;35:437-49.

53 Maroulakis $M$, Zervas Y. Effects of aerobic exercise on mood of adult women. Percept Mot Skills 1993;76:795-801.

54 Steinberg H, Sykes EA, LeBoutillier N. Exercise addiction: indirect measures of 'endorphins'? In: Annett J, Cripps B, Steinberg H, eds. Exercise addiction: motivation for participation in sport and exercise. Leeds: British Psychological Socition in sport and

55 Head A, Kendall MJ, Ferner R. Eagles C. Acute effects of Beta blockade and exercise on mood and anxiety. $\mathrm{Br} \mathcal{F}$ Sports Med 1996;30:238-42.

56 McAuley E, Mihalko SL, Bane, SM. Exercise and self-esteem in middle-aged adults: multidimensional relationships and physical fitness and self-efficacy influences. $\mathcal{F}$ Behav Med 1997;20:67-83.

57 Sonstroem RJ. Exercise and self-esteem. Exerc Sport Sci Rev 1984;12:123-55.

58 Gruber JJ. Physical activity and self-esteem development in children: a meta-analysis. In: Stull G, Eckert H, eds. Effects of physical activity on children: the Academy Papers No. 19. Co physical activity on children: the Academy Papers

59 Fox KR. Physical self-perception profile manual. Northern Illinois University: Office for Health Promotion, Dekalb, 1990.

60 Sonstroem RJ, Harlow LL, Gemma LM, et al. Test of structural relationships within a proposed exercise and selfesteem model. F Pers Assess 1991;56:348-64.

61 Sonstroem RJ, Speliotis ED, Fava JL. Perceived physical competence in adults: an examination of the Physical SelfPerception Profile. Fournal of Sport and Exercise Psychology 1992;14:207-21.

62 Sonstroem RJ, Harlow LL, Josephs, L. Exercise and self-esteem: validity of model expansion and exercise association. fournal of Sport and Exercise Psychology 1994;16:29-42.

63 Israel RG, Sutton M, O'Brien KF. Effects of aerobic training on primary dysmenorrhea symptomatology in college females. F Am Coll Health 1985;33:241-4.

64 Timmonen S, Procope B. Premenstrual syndrome and physical exercise. Acta Obstet Gynecol Scand 1971;50:3317.

65 Prior JC. Exercise-related adaptive changes to the menstrual cycle. In: Macleod D, Maughan R, Nimmo M, Reilly T, Williams C, eds. Exercise: benefits, limits and adaptations. London: Spon, 1987:239-54.

66 Choi PYL, Salmon P. Symptom changes across the menstrual cycle in competitive sportswomen, exercisers menstrual cycle in competitive sportswomen, exercisers

7 Shangold J. How I manage exercise amenorrhea. Physician and Sportsmedicine 1986;14:118-20.

68 Steptoe A, Cox S. Acute effects of aerobic exercise on mood. Health Psychol 1988;7:329-40.

69 Steptoe A, Bolton J. The short-term influence of high and low physical exercise on mood. Psychological Health 1988;2: 91-106.

70 Cockerill IM, Lawson SL, Nevill AM. Mood states, menstrual cycle and exercise-to-music. In: Annett B, Cripps B, Steinberg H, eds. Exercise addiction. Leeds: British Psychological Society, 1995:61-9.

71 Steege JF, Blumenthal JA. The effects of aerobic exercise on PMS in middle-aged women: a preliminary study. $\mathcal{F}$ Psychosom Res 1993;37:127-33.
72 Doyne EJ, Ossip-Klien DJ, Bowman ED, et al. Running Vs weight lifting in the treatment of depression. $\mathcal{F}$ Consult Clin weight lifting in the treat

73 Bonen A, Ling WY, MacIntyre KP, et al. Effects of exercise on the serum concentrations of FSH, LH, progesterone and estradiol. Eur $\mathcal{F}$ Appl Physiol 1979;42:15-23.

74 Baker ER, Mathur RS, Kirk RF, et al. Plasma gonadotropins, prolactin and steroid hormone concentrations in female runners immediately after a long-distance run. Fertil Steril 1982;38:38-41.

75 Cumming DC, Vickovic MM, Wall SR, et al. The effect of acute exercise on pulsatile release of luteinizing hormone in women runners. Am $\mathcal{f}$ Obset Gynecol 1985;153:482-5.

76 Wells CL. Women, sport and performance: a physiological perspective. Champaign, IL: Human Kinetics, 1985.

77 Rauramaa R. Relationship of physical activity, glucose tolerance and weight management. Prev Med 1984;13:37-46.

78 Reid RL, Yen SSC. The premenstrual syndrome. Clin Obstet Gynecol 1983;26:710-18.

79 Johnson E, Gannon LR. The endorphin theory of premenstrual syndrome: a synthesis of interdisciplinary research. Paper presented at the Association of Women's Psychology, New York, 1985

80 Tomlinson A. Introduction. In: Tomlinson A, ed. Gender, sport and leisure. Brighton: Chelsea School Research Centre, 1995:1-20.

81 Ryckman R, Hamel J. Male and female adolescents' motives related to involvement in organized team sports. International fournal of Sport Psychology 1995;26:383-97.

82 Scully DM, Clarke J. Gender issues. In: Kremer J, Trew K, Ogle S, eds. Young people's involvement in sport. London: Routledge, 1997:25-56.

83 Withdrawn.

84 Franzoi SL. The body-as-object versus the body-as-process: gender differences and gender considerations. Sex Roles $417-37$.

85 Frederick CJ, Shaw SM. Body image as a leisure constraint: examining the experience of aerobic exercise classes for young women. Leisure Science 1995;17:57.

86 McAuley E, Bane SM, Rudolph DL, et al. Physique anxiety and exercise in middle-aged adults. F Gerontol B Psychol Sci Soc Sci 1995;50:229-35.

87 Frederick CM, Morrison CS. Social physique anxiety: personality constructs, motivations, exercise attitudes and behaviours. Percept Mot Skills 1996;82:963-72.

88 Sonstroem RJ, Potts SA. Life adjustment correlates of physical self-concepts. Med Sci Sports Exerc 1996;28:61925 .

89 van Wersch A. Individual differences and intrinsic motivations for sport participation. In: Kremer J, Trew K, Ogle S, eds. Young people's involvement in sport. London: Routledge, 1997:57-77.

90 Biddle S, Goudas BA, Page BA. Social-psychological predictors of self report actual and intended physical activpredictors of self report actual and intended physical activity in a un $160-3$.

91 Koff E, Bauman C. Effects of wellness, fitness and sport skills programs on body image and lifestyle behaviours. Percept Mot Skills 1997;84:555-62.

92 Furnham A, Greaves N. Gender and locus of control correlates of body image dissatisfaction. European fournal of Personality 1994;8:183-200.

93 Cash TF, Henry PE. Women's body images: the results of a national survey in the U.S.A. Sex Roles 1995;33:19-28.

94 Cash TF, Deagle EA. The nature and extent of body-image disturbances in anorexia nervosa and bulimia

95 Koenig LJ, Wasserman EL. Body image and dieting failure in college men and women: examining links between depression and eating problems. Sex Roles 1995;32:225-49.

96 Arena B. Hormonal problems in young female athletes. Sports Exercise and Injury 1996;2:122-5.

97 Benson JE, Engelbert-Fenton KA, Eisenman PA. Nutritional aspects of amenorrhea in the female athlete triad. Int 7 Sport Nutr 1996;6:134-45.

98 Otis CL, Drinkwater B, Loucks A, et al. ACSM position stand: the female athlete triad. Med Sci Sports Exerc $1977 ; 29: 1-4$.

99 Nattiv A. The female athlete triad: managing acute risk to ong-term health. Physician and Sportsmedicine 1995;22:608.

100 Davis C, Kennedy SH, Ravelski E, et al. The role of physical activity in the development and maintenance of eating disorders. Psychol Med 1994;24: 957-67.

101 Davis C. Eating disorders and hyperactivity: a psychobiological perspective. Can f Psychiatry 1997;42:168-75.

102 Troop NA, Holbrey A, Trowler R, et al. Ways of coping in women with eating disorders. F Nerv Ment Dis 1994;182

103 Willcox M, Sattler DN. The relationship between eating disorders and depression. F Soc Psychol 1996;136:269-71. 04 Annett J, Cripps B, Steinberg H. Exercise addiction. Leeds: British Psychological Society, 1995.

105 Morgan WP, ed. Physical activity and mental health. Washington, DC: Taylor \& Francis, 1996.

106 Grossman A, Bouloux P, Price P. The role of opioid peptides in the hormonal responses to acute exercise in man. Clin Sci 1984;67:483-91.

107 Grant E. The exercise fix. Psychogy Today 1992;22:24-8.

108 Sachs ML, Pargman D. Running addiction: a depth interview examination. Fournal of Sport Behavior 1979;2:14355.

109 Veale DMW. Exercise dependence. British fournal of Addiction 1987;82:735-40. 
110 Davis C, Kennedy SH, Ralevske E, et al. Obsessive compulsiveness and physical activity in anorexia nervosa

111 Veale DMW. Does primary exercise dependence really exist? In: Annett J, Cripps B, Steinberg H. Exercise addiction. Leeds: British Psychological Society, 1995:1-5.

112 Little JC. The athlete's neurosis: a deprivation crisis. Acto Psychiatr Scand 1969;45:187-97.

113 Mondin GW, Morgan WP, Piering PN, et al. Psychological consequences of exercise deprivation in habitual exercisers. Med Sci Sports Exerc 1996;28:1199-203.

114 Chan CS, Grossman HY. Psychological effects of running loss on consistent runners. Percept Mot Skills 1988;66:87588.

115 Morris M, Steinberg H, Sykes EA, et al. Effects of temporary withdrawal from regular running. 7 Psychosom Res 1990;34:493-500.

116 Robbins JM, Joseph P. Experiencing exercise withdrawal: possible consequences of therapeutic and mastery running. possible consequences of therapeutic and
fournal of Sport Psychology 1985;7:25-39.

117 Annett J. Summing up. In: Annett J, Cripps B, Steinberg H. Exercise addiction. Leeds: British Psychological Society,

118 Steinberg H, Sykes EA, LeBoutillier N. Exercise addiction: indirect measures of 'endorphins'. In: Annett J, Cripps B, Steinberg H. Exercise addiction. Leeds: British Psychological Society, 1995:6-14.
119 Berger BG, McInman A. Exercise and the quality of life. In: Singer RN, Murphy M, Tennant LK, eds. Handbook of research on sport psychology. New York: Macmillan, 1993: 729-60.

120 McGeorge S, Harris J, Clark F. Physical activity protocols for primary care. Loughborough: Department of Physical Education, Loughborough University, 1994.

121 Marcus BH, Simkin LR. The stages of exercise behaviour. f Sports Med Phys Fitness 1993;33:83-8.

122 British Heart Foundation. GP advice on exercise is worth more than $£ 1000$. General Practitioner 1996;Jul $12: 24$.

123 Health Education Authority. Active for life. London: HEA, 1996.

124 Hammond JM, Brodie DA, Bundred PE. Exercise on prescription: guidelines for health professionals. Health Promotion International 1997;12:33-41.

125 Iliffe S, Tai SS, Gould M, et al. Prescribing exercise in general practice. BMF 1994;309:494-5.

126 Sunday Times. Doctor in the gym. Style Supplement 1997; Sep 14:30-1.

127 Etnier JL, Salazar W, Landers DM, et al. The influence of physical fitness and exercise upon cognitive functionning: a meta-analysis. Fournal of Sport and Exercise Psychology 1997;19:249-77.

\section{A healthy mind; a healthy body_-and what else?}

Virtually everyone with a background in sports or exercise related studies will be familiar with the phrase "a healthy mind in a healthy body". Most will also recognise that this is a translation of the Latin "mens sana in corpore sano". Some will even properly attribute the phrase to Juvenal (Decimus Junius Juvenalis), the great Roman satirist of the 1st and 2nd century AD, and some specifically to the 10th of his 16 Satires (other Satires also contain comments (almost invariably sardonic) on sports related issues, such as "athletes' diets" in Satire II). But one wonders how many of those who extol the virtues of this famous phrase would be similarly enthusiastic about the sentiments expressed in the remainder of the sentence from which it originates.

Having queried "Is there nothing worth praying for, then?", Juvenal concludes that "... if you must have something to pray for .... then ask for a sound mind in a sound body, a valiant heart without fear of death, that reckons longevity the least among Nature's gifts, that's strong to endure all kind of toil, that's untainted by lust and anger, that prefers the sorrows and labours of Hercules to all Sardanapalus' downy cushions and women and junketings." (NB some scholars prefer to translate "sana" as "sound" rather than "healthy".)

And so, as sports and exercise scientists, are we prepared to pray for and promulgate:

- "a healthy mind in a healthy body"? Without exception one would imagine.

- Reckon longevity the "least among Nature's gifts"? Probably not-not "the least", anyway.

- "strong to endure"? Of course.

- "untainted by lust ..."? Few would pray for that!

- Prefer "the sorrows and labours of Hercules" to "all Sardanapalus' downy cushions and women and junketings"? It would be interesting to learn the result of a vote on that one.

It is clear from the whole sentence, therefore, that the satirist beckons us across the millennia, tongue firmly in cheek, demanding that "mens sana ....." be considered in, rather than out of, context.

BRIAN J WHIPP

Department of Physiology, St George's Hospital Medical School

1 Juvenal. The sixteen Satires. Translated by Peter Green. Harmondsworth: Penguin Books Ltd, 1967. 